\title{
Resveratrol Hinders Postovulatory Aging by Modulating Oxidative Stress in Porcine Oocytes
}

\author{
Benazir Abbasi, Yan Dong and Rong Rui * \\ College of Veterinary Medicine, Nanjing Agricultural University, Nanjing 210095, China; \\ benazirabbassi@gmail.com (B.A.); 2016107099@njau.edu.cn (Y.D.) \\ * Correspondence: rrui@njau.edu.cn; Tel.: +86-25-843-955-95
}

Citation: Abbasi, B.; Dong, Y.; Rui, R Resveratrol Hinders Postovulatory Aging by Modulating Oxidative Stress in Porcine Oocytes. Molecules 2021, 26, 6346. https://doi.org/ $10.3390 /$ molecules 26216346

Academic Editors: Norbert Latruffe and Paula Silva

Received: 21 August 2021

Accepted: 18 October 2021

Published: 20 October 2021

Publisher's Note: MDPI stays neutral with regard to jurisdictional claims in published maps and institutional affiliations.

Copyright: (c) 2021 by the authors. Licensee MDPI, Basel, Switzerland. This article is an open access article distributed under the terms and conditions of the Creative Commons Attribution (CC BY) license (https:// creativecommons.org/licenses/by/ $4.0 /)$.

\begin{abstract}
Postovulatory aging of the mammalian oocytes causes deterioration of oocytes through several factors including oxidative stress. Keeping that in mind, we aimed to investigate the potential of a well-known antioxidant, resveratrol (RV), to evaluate the adverse effects of postovulatory aging in porcine oocytes. After in vitro maturation (IVM), a group of (25-30) oocytes (in three replicates) were exposed to $0,1,2$, and $4 \mu \mathrm{mol} / \mathrm{L}$ of $\mathrm{RV}$, respectively. The results revealed that the first polar body (PB1) extrusion rate of the oocytes significantly increased when the RV concentration reached up to $2 \mu \mathrm{mol} / \mathrm{L}(p<0.05)$. Considering optimum RV concentration of $2 \mu \mathrm{mol} / \mathrm{L}$, the potential of $\mathrm{RV}$ was evaluated in oocytes aged for 24 and $48 \mathrm{~h}$. We used fluorescence microscopy to detect the relative level of reactive oxygen species (ROS), while GHS contents were measured through the enzymatic method. Our results revealed that aged groups ( $24 \mathrm{~h}$ and $48 \mathrm{~h})$ treated with RV $(2 \mu \mathrm{mol} / \mathrm{L})$ showed higher $(p<0.05)$ ROS fluorescence intensity than the control group, but lower $(p<0.05)$ than untreated aged groups. The GSH content in untreated aged groups ( $24 \mathrm{~h}$ and $48 \mathrm{~h}$ ) was lower $(p<0.05)$ than RV-treated groups, but both groups showed higher levels than the control. Similarly, the relative expression of the genes involved in antioxidant activity (CAT, GPXGSH-Px, and SOD1) in RV-treated groups was lower $(p<0.05)$ as compared to the control group but higher than that of untreated aged groups. Moreover, the relative mRNA expression of caspase- 3 and Bax in RV-treated groups was higher $(p<0.05)$ than the control group but lower than untreated groups. Furthermore, the expression of $\mathrm{Bcl}-2$ in the RV-treated group was significantly lower than control but higher than untreated aged groups. Taken together, our findings revealed that the RV can increase the expression of antioxidant genes by decreasing the level of ROS, and its potent antiapoptotic effects resisted against the decline in mitochondrial membrane potential in aged oocytes.
\end{abstract}

Keywords: resveratrol; postovulatory aging; oocyte quality; oxidative stress; reactive oxygen species

\section{Introduction}

The postovulation oocyte quality is the main factor that affects the efficiency of assisted reproductive technologies (ART) such as somatic cell nuclear transfer (SCNT), intracytoplasmic sperm injection (ICSI), and in vitro fertilization (IVF) [1,2]. The quality of an oocyte is mainly affected by structural and functional changes induced during aging including chromosome and spindle anomalies [3], cortical granule exocytosis [4], lower fertilization rates [5], zona pellucida (ZP) hardening [6], and abnormal or retarded development of embryos/fetuses [7,8]. The exact molecular mechanism underlying the reduced competence of an oocyte due to postovulatory aging is not fully understood. However, there are some major factors that mediate time dependent reduction in oocyte competence such as oxidative stress [9], chromosomal abnormalities [10], and modification of poly (A) tails (Deadenylation) of genes responsible for maternal effects [11] and epigenetic alteration $[12,13]$. Therefore, it is imperative to better understand the various mechanisms responsible for the postovulatory aging process to devise effective strategies to delay oocyte aging process and increase the time required for performing normal reproductive 
functions $[9,14]$. Oxidative stress is strongly associated with a deterioration in oocyte quality because it significantly reduces the glutathione (GSH) contents and assists in the accumulation of reactive oxygen species (ROS). The ROS such as superoxide anions $\left(\mathrm{O}^{-2}\right)$, hydroxyl radicals $\left(\mathrm{OH}^{-}\right)$, and hydrogen peroxide $\left(\mathrm{H}_{2} \mathrm{O}_{2}\right)$ are released during normal metabolic (intermediate steps of oxygen reduction) processes $[15,16]$. The mitochondrion is the major cell organelle responsible for ROS production [17,18]. A dynamic balance is required between ROS production and antioxidant enzymes to ensure proper cellular homeostasis including cell proliferation, host defense, signal transduction, and gene expression [19]. The antioxidant defense system disrupted through the overproduction of ROS, which, in turn, causes oxidative stress. Excessive load of ROS results in proapoptotic signaling, subsequently leading to the activation of cell apoptosis [20]. Postovulatory aging is associated with excessive accumulation of ROS leading to oxidative stress, which predisposes aged oocytes to the apoptotic process $[9,21]$. The mitochondria as the major "energy generators" have a significant role in regulating proper function and survival of oocytes. However, being a prime source of ROS production, mitochondria are susceptible to ROS-induced damage [22], which results in the decreased ATP synthesis, altered mitochondrial membrane potential, oxidative stress, and early onset of apoptosis $[23,24]$. The excessive accumulation of ROS can affect the permeability of mitochondrial membranes to open MPTP (1-methyl-4-phenyl-1,2,3,6-tetrahydropyridine) and promote the flow of calcium ions [25], which subsequently induces the release of cytochrome $C$ and caspase 3 activation leading to the apoptosis [26,27]. The apoptotic activation is mainly induced by the glutathione efflux [28], which leads to several morphological changes including cell shrinkage, progressive DNA, and cell membrane damage, ultimately leading to the cell death [29]. Therefore, one of the major challenges in reproductive embryology is to prevent oocytes' degeneration to maintain their developmental competences [30]. To avoid oxidative damage by maintaining a robust antioxidant defense system in the oocyte, supplementation of exogenous antioxidants can be used as the most effective strategy.

Resveratrol (3,5,4'-trihydroxyl-Trans-stilbene) (RV) is a stilbenoid, a type of natural polyphenolic compound with excellent antioxidant and free radical scavenging capacity. It is associated with reduced ROS accumulation, scavenges superoxide radicals, inhibits lipid peroxidation, and regulates the expression of antioxidant cofactors and enzymes [31]. Natural antioxidants that are effective may provide novel and safe interventional strategies to delay or prevent oocyte aging and related diseases. Porcine oocytes can be used as an ideal model in the field of reproductive biology, as they have much similar developmental and physiological properties as with human oocytes [32]. Therefore, this study was conducted to evaluate the effect of RV on pig oocytes during aging and to provide mechanistic insights regarding its potential of protecting oocytes against ROS attack. Reducing oxidative stress in the oocytes is an important way to slow down oocyte aging. Still, there is lack of data regarding the rescue of oocytes during aging. The underlying mechanisms of oxidative stress during oocyte aging as well as the protective mechanisms of the natural antioxidants in antiaging are thoroughly explored in the present study.

\section{Results}

\subsection{RV Treatment Reverses Aging-Induced Impairment in Aged Porcine Oocytes}

For determining the optimal concentration of RV, which can delay oocyte age dependent impairments, the cumulus cells incubated for $44 \mathrm{~h}$ were removed with $0.1 \%(w / v)$ hyaluronidase using $37^{\circ} \mathrm{C}$ for $3 \mathrm{~min}$. The oocytes with even granular cytoplasm and a first polar body were selected for the subsequent experiments. During in vitro maturation, a total of 25-30 oocytes (in three replicates) for each group were cultured with $0,1,2$, and $4 \mu \mathrm{mol} / \mathrm{L} \mathrm{RV}$, respectively. After maturation, the proliferation rate of cumulus oocyte complexes (COCs) was observed under a stereomicroscope. As shown in Figure 1a, most of the COCs showed fully expanded peripheral layers of cumulus in 1 and $2 \mu \mathrm{mol} / \mathrm{L}$ RV-treated groups, whereas the cumulus proliferation of COCs was significantly decreased in the control and $4 \mu \mathrm{mol} / \mathrm{L}$ of RV-treated group. In addition, a large proportion of the RV-treated 
oocytes failed to extrude the PB1 in a dose-dependent manner. As shown in Figure 1b, percentage of the PB1 extrusion rate was significantly higher in the $2 \mu \mathrm{mol} / \mathrm{L}$ RV-treated group $(78.99 \pm 1.07)$ as compared to the control group $(71.26 \pm 1.02 \%)$. However, there was no significant difference observed for these parameters in 1 and $4 \mu \mathrm{mol} / \mathrm{L}$ RV-treated groups (73.95 $\pm 1.05 \%$ and $73.76 \pm 1.02$, respectively).

a

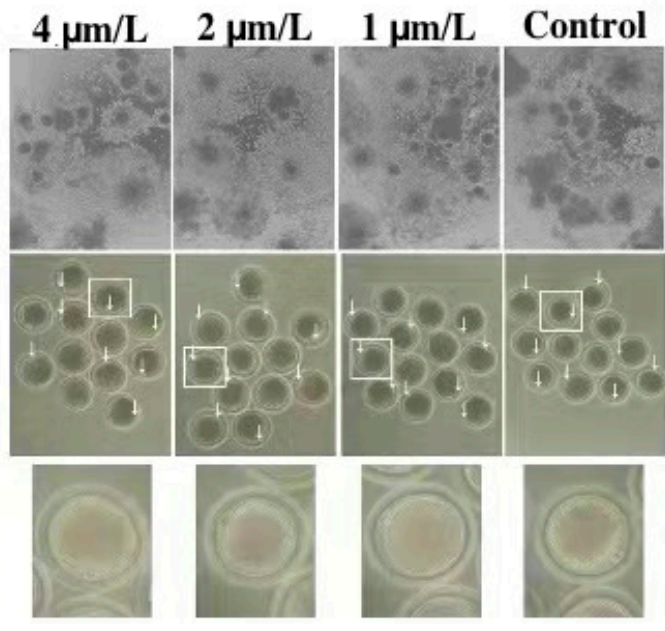

Figure 1. RV treatment reverses aging-induced impairment in aged porcine oocytes. (a) The representative images showing degrees of cumulus spread and first polar body extrusion rate, as indicated by white arrows. (b) The graph showing PB1 extrusion percentage rate at various concentrations $(0,1,2$, and $4 \mu \mathrm{mol} / \mathrm{L} \mathrm{RV})$. Significant difference $\left({ }^{*} p<0.05\right)$.

\section{2. $R V$ Suppresses the Increasing Perivitaline Space (PVS) in Aged Porcine Oocytes}

As shown in Figure 2a, arrows indicate the significantly increased perivitaline space in oocytes of $24 \mathrm{~h}$ and $48 \mathrm{~h}$ aged groups (15.98 \pm 0.60 and $21.51 \pm 1.16$, respectively) as compared to the control group (10.94 \pm 0.53$)$. Moreover, the treatment with $2 \mu \mathrm{mol} / \mathrm{L}$ of $\mathrm{RV}$ prolonged oocyte culture ( $24 \mathrm{~h}$ and $48 \mathrm{~h}$ ) can significantly suppress the perivitaline space when compared with untreated $(24 \mathrm{~h}$ and $48 \mathrm{~h}$ ) aged groups.

$\mathbf{a}$

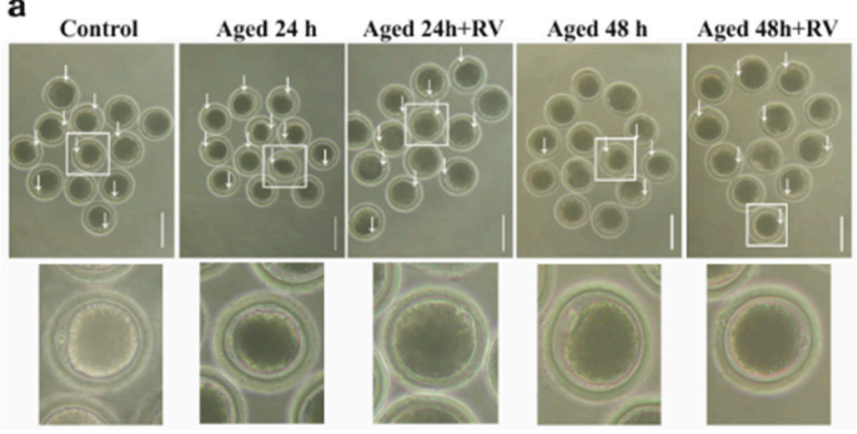

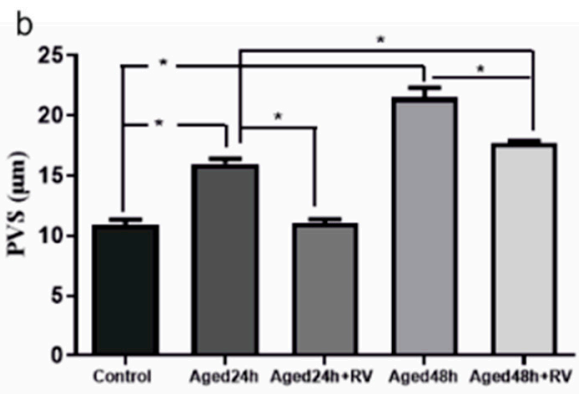

Figure 2. RV suppresses the increasing perivitaline space (PVS) in aged porcine oocytes (a) The representative images of perivitaline space in aged porcine oocytes with visible space indicated by white arrows under the microscope, scale bar $=180 \mu \mathrm{m}$. (b) The graph indicates the percent increase in perivitaline space after the oocytes treated with $2 \mu \mathrm{mol} / \mathrm{L}$ RV. Significant difference $\left({ }^{*} p<0.05\right)$.

\subsection{RV Reduces the Apoptosis Extent in Aged Porcine Oocytes}

The apoptosis includes a series of cellular apoptotic events that occur during oocyte aging during in vitro maturation [33]. As shown in Figure 3 the mRNA expression of apoptosis related genes (Caspase-3, Bax, and Bcl-2) were analyzed through qRT-PCR to determine the cellular activities during the RV treatment. The results showed that the mRNA levels of Caspase- 3 and Bax treated with $2 \mu \mathrm{mol} / \mathrm{L} \mathrm{RV}$ were significantly higher than those in the control group but significantly lower than those in the $24 \mathrm{~h}$ and $48 \mathrm{~h}$ aged 
groups, while the expression of Bcl-2 was significantly lower. Moreover, the expression of Bcl-2 group oocytes treated with $2 \mu \mathrm{mol} / \mathrm{L} \mathrm{RV}$ was significantly lower than that in control but significantly higher than that in the untreated aged groups.

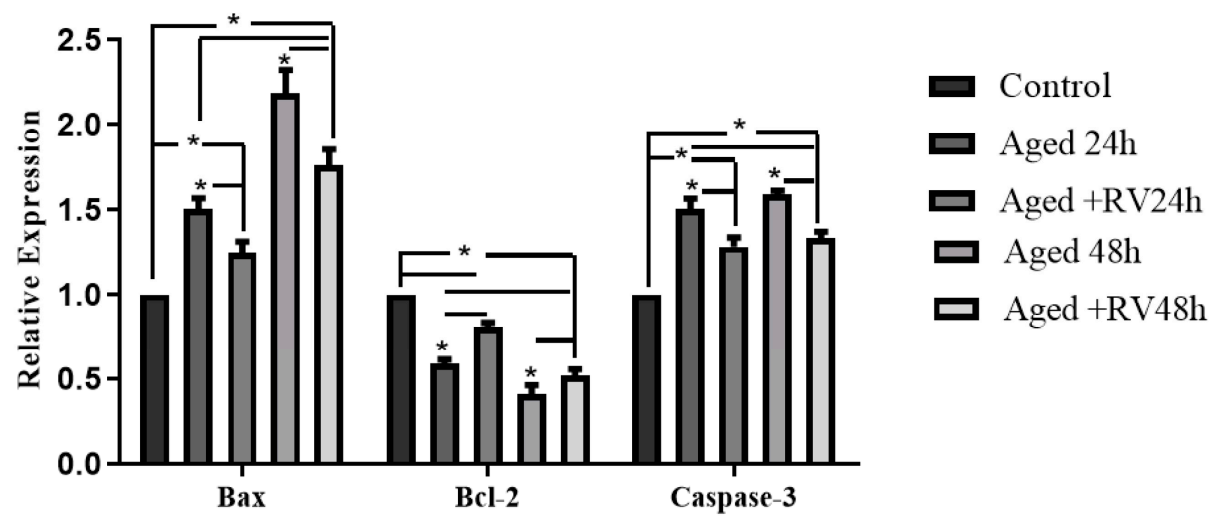

Figure 3. The relative mRNA expression of apoptosis related (Caspase-3, Bcl-2, and Bax) genes in aged porcine oocytes at different time periods. Significant difference $\left({ }^{*} p<0.05\right)$.

\subsection{RV Alleviates the Oxidative Stress in Aged Porcine Oocytes}

$\mathrm{RV}$ is known to protect cells against oxidative stress and to determine whether RV can protect porcine oocyte against oxidative stress. We first measured the levels of intracellular ROS, as shown in Figure $4 \mathrm{a}, \mathrm{b}$; the levels of ROS were significantly higher in the $24 \mathrm{~h}$ and $48 \mathrm{~h}$ untreated aged groups when compared with the control group, while the oocytes treated with $2 \mu \mathrm{mol} / \mathrm{L} \mathrm{RV} \mathrm{(24} \mathrm{and} 48 \mathrm{~h}$ ) showed significantly higher fluorescence intensity levels as compared to the control group but significantly lower intensity as compared to the untreated aged groups. The glutathione (GSH) is an important intracellular antioxidant because it exerts powerful functions for protecting the cells from the oxidative stress-induced damage, and so the GSH and GSSG kits were used to detect the ROS levels. Surprisingly, our analysis for ROS levels using GSH and GSSG kit shows that the intracellular levels of GSH in the $24 \mathrm{~h}$ and $48 \mathrm{~h}$ untreated aged groups were significantly lower when compared with the control group (Figure 4c). The GSH content in the $24 \mathrm{~h}$ and $48 \mathrm{~h}$ groups treated with $2 \mu \mathrm{mol} / \mathrm{L}$ of RV was significantly higher than that in the $24 \mathrm{~h}$ and $48 \mathrm{~h}$ untreated aged groups. In addition, we also determined the mRNA expression of antioxidant and oxidative stress related genes (CAT, GPX, and SOD1) by qRT-PCR analysis. Our results (Figure $4 \mathrm{~d}$ ) showed that the mRNA transcript levels of CAT and SOD1 groups' oocytes treated with $2 \mu \mathrm{mol} / \mathrm{L}$ RV were significantly higher than those in the untreated aged groups; however, the expression of CAT and SOD1 was lower as compared to the control group. Likewise, there was a significant increase in the treated groups of GPX, and no difference was found between the untreated aged GPX and control groups.

\subsection{RV Rescues the Mitochondrial Membrane Potential in Aged Porcine Oocytes}

It is well-known that oxidative stress is associated with mitochondrial membrane potential (MMP) changes and cell apoptosis. Therefore, we intended to determine the mitochondrial membrane potential state during porcine oocyte aging. To investigate the mitochondrial membrane potential, we analyzed the ratio of red/green fluorescence. As shown in Figure 5c,e,h,j,k, the oocytes treated with $2 \mu \mathrm{mol} / \mathrm{L} \mathrm{RV}(24 \mathrm{~h}$ and $48 \mathrm{~h}$ ) aged groups showed lower ratios than those in the untreated aged groups. Moreover, oocytes in control (Figure 5a,f,k) showed the lowest values. Based on our findings, this is concluded that RV has remarkable efficacy on keeping mitochondrial membrane potential in porcine oocyte aging. 


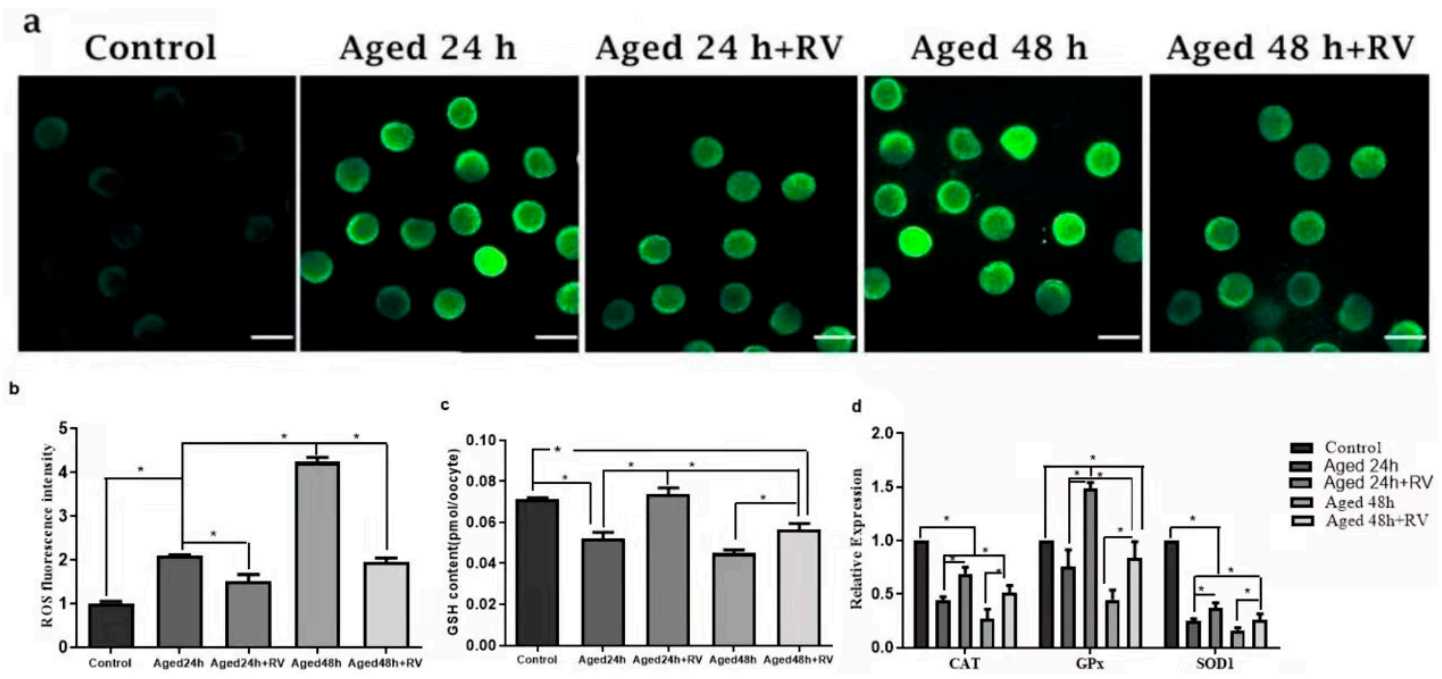

Figure 4. RV alleviates the oxidative stress in aged porcine oocytes. (a) The representative images of ROS in aged porcine oocytes. (b,c) The graphs showing quantified intracellular levels of ROS and GSH in aged porcine oocytes. (d) The graph showing relative mRNA expression of oxidative stress related (CAT, GPX, and SOD1) genes in aged porcine oocytes. ROS levels were quantified by relative fluorescence intensity in porcine oocytes, scale bar $=280 \mu \mathrm{m}$. Each experiment was independently repeated at least three times. Significant difference $\left({ }^{*} p<0.05\right)$.

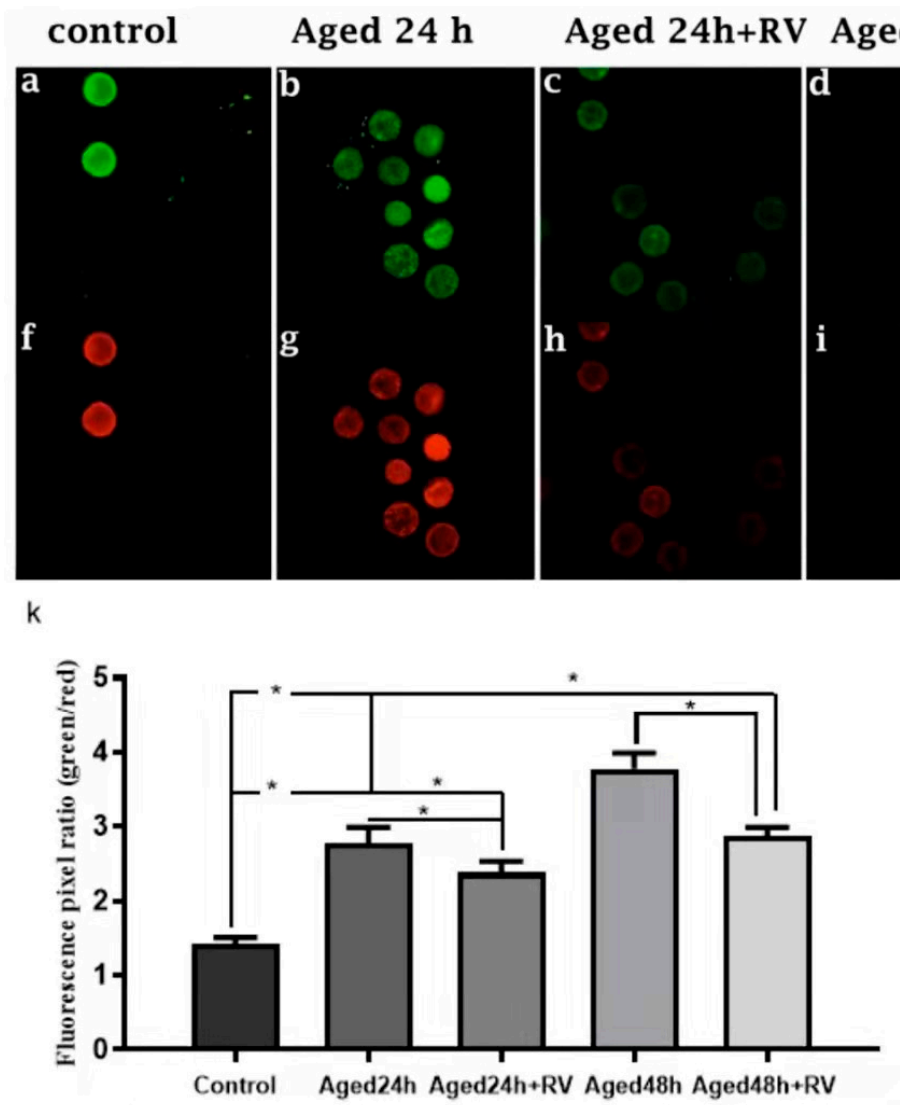

Figure 5. RV rescues the mitochondrial membrane potential in aged porcine oocytes. Representative Fluorescent images of JC-1-stained oocytes. Cultured in the absence or presence of $2 \mu \mathrm{mol} / \mathrm{L} \mathrm{RV}$. (a,f) Control; (b,g) aged 24 h; (c,h) aged $24 \mathrm{~h}+\mathrm{RV} ;(\mathbf{d}, \mathbf{i})$ aged $48 \mathrm{~h} ;(\mathbf{e}, \mathbf{j})$ aged $48 \mathrm{~h}+\mathrm{RV}$. (k) Quantitative analysis of JC-1 red/green fluorescence intensity ratio in porcine oocytes. Membrane potential was calculated as the ratio of red fluorescence, which corresponds to activated mitochondria (J-aggregates), and to green fluorescence, which corresponds to less-activated mitochondria (J-monomers). Fluorescence emitted from each oocyte was analyzed using the ImageJ software. Significant difference $(* p<0.05)$. 


\section{Discussion}

One of the main aspects of ovarian aging is the decline in fertility over time, which is characterized by the decline in the quality and quantity of oocytes [34]. However, some evidence suggests that an imbalance between ROS and antioxidants causes a decline in oocyte quality, which is a critical factor in the success of ART and is linked to the aging of the ovaries. Furthermore, the RV as an antioxidant has been proved to alleviate oxidative stress in various cell types including oocytes. Moreover, RV has shown to prevent mitochondrial damage in cardiomyocytes through the upregulation of the deacetylation of apoptotic proteins. Studies have revealed that treatment of porcine oocytes with $2 \mu \mathrm{mol} / \mathrm{L} \mathrm{RV} \mathrm{signifi-}$ cantly reduced the levels of intracellular ROS while increased GSH contents during in vitro maturation $[35,36]$. In our study, we revealed that, under in vitro conditions, $2 \mu \mathrm{mol} / \mathrm{L} \mathrm{RV}$ was able to delay postovulatory oocyte aging, owing to possible mechanisms mediated by reducing oxidative stress. RV could significantly increase the GSH content in $24 \mathrm{~h}$ and $48 \mathrm{~h}$ aged groups treated with $2 \mu \mathrm{mol} / \mathrm{L}$ of RV as compared with the control group $(p<0.05)$. The certain survival factors and antiapoptosis factors lead to oocyte maturation disorder or apoptosis by a decrease in mature-promoting factor (MPF) stability [37]. Furthermore, induced oxidative stress can adversely affect a variety of reproductive processes including sperm capacitation, ovulation, and corpus luteum production and can also trigger oocyte apoptosis. The accumulation of ROS has serious manifestation regarding the quality and aging of oocytes [38]. The uncontrolled and excessive production of free radicals may harm DNA, proteins, and lipids, which can severely compromise cell health and contribute to the disease development [39-41]. Our results showed that RV can significantly reduce the ROS level in aged oocytes ( 24 and $48 \mathrm{~h}$ ), which is consistent with previous findings [42]. Similarly, RV (at concentrations $\geq 100 \mu \mathrm{M}$ ) has been shown to scavenge O2 directly in a nonenzymatic, cell-free system [43]. Findings in the present study indicate the potential of $\mathrm{RV}$ to delay oocyte aging by reducing ROS levels owing to its reported antioxidant [44], antiapoptosis [45], and antiaging [42] activities. Moreover, RV has also shown to reduce lipid peroxidation by eliminating free radicals and thus achieve the effect of protecting cells [46]. The main antioxidant enzymes are $S O D$, catalase (CAT), and glutathione peroxidase (GPX). Moreover, $\mathrm{O}_{2}$ is converted by $\mathrm{SOD}$ to $\mathrm{H}_{2} \mathrm{O}_{2}$, which is decomposed to water and oxygen by $C A T$, preventing the production of hydroxyl radicals. In addition, GPX transforms peroxides and hydroxyl radicals into nontoxic forms by oxidizing reduced glutathione (GSH) into glutathione disulfide and triggers reduction to GSH by glutathione reductase [47]. When $\mathrm{Cu}^{+2}$ or Fe$e^{+2}$ are available, $\mathrm{H}_{2} \mathrm{O}_{2}$ reacts with these ions to form unstable hydroxyl radicals. Previous studies have shown that RV can increase the expression of various antioxidant genes such as CAT, SOD, and GPX in cells [48,49]. When low-dose of RV was used to treat cardiomyocytes, the catalytic activity of $C A T$ and $S O D$ increased significantly with no effect on glutathione activity. Moreover, $S O D$ can reduce intracellular superoxide levels and potentially resist against cell apoptosis, membrane permeability changes, and mitochondrial dysfunction [50]. Previous studies in our laboratory have demonstrated that RV can eliminate mitochondrial injury while delaying oocyte aging and improving the expression of sirtuin-1 (sirt1) and thus the quality of aged porcine oocytes [1]. Similarly, in the present study, RV treatment increased the expression of GPX gene in $24 \mathrm{~h}$ aged groups as compared to the control and untreated aged groups $(p<0.01)$. However, the expression of $C A T$ and SOD1 genes was lower than that of the control group $(p<0.05)$ but still higher than their untreated counterparts. Likewise, RV increases GSH content in primary keratinocytes and in epidermis of a reconstructed skin model as reported previously [51]. The antioxidant response of RV was further confirmed through enhanced activity of SOD with administration of 2-NP in a rat model conducted by Lodovici et al. [52]. Our findings revealed that RV can effectively mediate oxidative stress induced by the aging oocytes during in vitro culture through increasing the antioxidant gene expression. Progesterone causes elongation of the Mos poly (A) tail via cytoplasmic polyadenylation, and this polyadenylation increases the rate of Mos translation leading to the accumulation of Mos protein [53]. Mos protein is essentially required for the initiation of oocyte germinal vesicle breakdown [54]. In 
our study, we observed an increase in cumulus spread after treatment of oocytes with different concentrations of $\mathrm{RV}(0,1,2$, and $4 \mu \mathrm{mol} / \mathrm{L})$, which is consistent with previous findings, as mentioned earlier. Furthermore, PB1 extrusion rate with $2 \mu \mathrm{mol} / \mathrm{L}$ of RV group was also significantly higher than other groups, indicating the potential of RV to increase oocyte maturation rate in a dose-dependent manner. During this study, we found that oocytes treated with RV showed a significant decrease in perivitaline spaces during $24 \mathrm{~h}$ and $48 \mathrm{~h}$ of aging. However, differences were nonsignificant compared with the control group. A full expansion of cumulus cells is mandatory for the proper maturation of the oocyte. The beneficial effects of RV might depend upon its ability to improve oocyte quality. Therefore, it can be concluded that RV $(2 \mu \mathrm{mol} / \mathrm{L})$ can inhibit the increase of perivitaline space of oocytes aged for $24 \mathrm{~h}$ and $48 \mathrm{~h}$, indicating its ability to alleviate the adverse effects of postovulatory oocyte aging by improving the quality, which is necessary for its development during fertilization. Apoptosis is well-known for exogenous (mediated by death receptors) and mitochondria-guided endogenous pathways. Both of these pathways participate in the activation of certain members of the Caspase family to trigger apoptosis. The proteins involved in the mitochondria-mediated endogenous pathway include the member of the Bcl-2 family, which comprises both antiapoptotic and proapoptotic proteins. The antiapoptotic proteins (Bcl-XL, Bcl-2, and Mcl-1) potentially inhibit the activation of the Caspase family and block the transduction of apoptotic signals, while proapoptotic proteins (Bcl XS, Bak, Bax, and Bad) promote and initiate an apoptotic response. Caspase 3 acts as a key effector in the process of apoptosis and directly hydrolyzes specific substrates. When there is apoptosis, Bax acts on the outer mitochondrial membrane of cell causing the release of mitochondrial cytochrome $\mathrm{C}$ (Cytc) that activates Caspase 3 and triggers Caspase cascade. The nucleated cytoskeleton recombines and degrades cytoskeletal structure [33]. However, Bcl 2 inhibits Cytc and Caspase, causing an antiapoptotic effect. The recruitment of Bax, which is knocked out, restricts the expression of Bax and leads to an increase in the number of ovarian oocytes [55]. Deacetylated Sirt1 and Sirt-3 inhibit the apoptotic pathway by affecting 1-methyl-4-phenyl-1, 2, 3, 6-tetrahydropyridine (MPTP) pores of the mitochondrial membrane [56]. Furthermore, downregulation of caspase 3 upregulates the expression of the antiapoptotic protein such as Bcl-2 that subsequently inhibits apoptosis. We observed lower expression of Bax and Caspase 3 in RV-treated aged oocytes in the present study. Moreover, relative mRNA expression of Bcl-2 was significantly lower in the RV-treated group than the control but was significantly higher as compared to untreated aged groups. Our findings suggested that RV can effectively inhibit mitochondrial apoptotic pathway through downregulation of the Bax and Caspase 3 while upregulating the expression of Bcl-2 in aged oocytes, eventually reducing the adverse effects of aging in porcine oocytes. Mitochondria are responsible for maintaining cellular metabolic functions, and their physiological efficiency can be assessed by examining the mitochondrial membrane potential state. In this regard, fluorescence probes such as JC- 1 tend to accumulate in the mitochondrial matrix (by forming I-J-aggregates) and produce red excitation light when the mitochondrial membrane potential is maintained high. However, if mitochondrial membrane potential is maintained low, JC-1 cannot accumulate in the mitochondrial matrix and, hence, forms monomers and generates green excitation light. On the basis of these results is suggested a remarkable efficacy of RV on keeping mitochondrial membrane potential in porcine oocyte aging. During the present study, inclusion of RV in the oocyte culture medium maintained the mitochondrial membrane potential of aged oocytes in a state consistent with nonaged counterparts. Furthermore, RV significantly increased the expression of Bcl-2 in 24 and $48 \mathrm{~h}$ aged oocytes, which subsequently can modulate the mitochondrial apoptotic pathway by controlling the permeability of the outer mitochondrial membrane [57]. Consequently, the RV-regulated follicular development primarily through increased expression of mitochondrial-related Bcl-2 gene, which might have played its role in the maintenance of mitochondrial membrane potential in its normal position in 24 and $48 \mathrm{~h}$ aged oocytes. However, further in vivo studies are required to elucidate its potential mechanism of action. 


\section{Materials and Methods}

\subsection{Ethics Statement}

The present study (short title: "Resveratrol hinders postovulatory aging by modulating oxidative stress in porcine oocytes") was carried out in strict accordance with the recommendation of the National Ethical commission of (Nanjing, Jiangsu, China). All the experiments and procedures compiled with the guideline and were approved by the local ethical committee of the Nanjing Agricultural University (Nanjing, Jiangsu, China) with respect to animal experimentation and care of animal under study.

\subsection{Reagents}

Resveratrol (R5010, Sigma, purity $\geq 99 \%$ ), Dulbecco's PBS (DPBS), Hyaluronidase H-3506, DMSO D2650, paraformaldehyde 158127, poly vinyl alcohol (PVA) 046K0086, D-Mannitol M-9647, and Sodium pyruvate 100M12532V were purchased from SigmaAldrich (St. Louis, MO, USA), unless otherwise mentioned.

\subsection{Oocytes Collection and IVM}

The porcine ovaries were collected from prepubertal gilts at a local slaughterhouse of (Nanjing Yuan-run Group Co., Ltd., Nanjing, China) and transported to our laboratory at $37{ }^{\circ} \mathrm{C}$ in $0.9 \% \mathrm{NaCl}(w / v)$ physiological saline within $2 \mathrm{~h}$ postcollection. Follicular fluid from superficial follicles of 3-6 $\mathrm{mm}$ in diameter was aspirated using a disposable syringe with an 18-guage needle, and the fluid was immediately transferred into conical tubes to allow COCs to settle down at the bottom for quick (pick up purpose) of COCs. After 10-12 min, the whole bottom sediment was placed down in petri dish. Follicular contents containing COCs that had more than 3 unexpanded cumulus cell layers with uniform cytoplasm were selected under a stereomicroscope (Olympus, Tokyo, Japan) and washed thrice in HEPES buffered Tyrode's medium containing 0.05\% $(w / v)$ PVA (TLHPVA). A group of approximately 50-70 of COCs was placed in each well in a 4-well plate (Nunclon, Roskilde, Denmark) containing $500 \mu \mathrm{L}$ pre-equilibrated TCM199 medium (Gibco NY, USA) supplemented with 3.05 Mm D-glucose, 0.91 Mm sodium pyruvate, $0.57 \mathrm{Mm}$ cysteine, $10 \mathrm{ng} / \mathrm{mL}$ epidermal growth factor, $10 \mathrm{IU} / \mathrm{mL}$ PMSG and hCG (Ningbo Hormonal Reagents Co., Ltd., Ningbo, Zhejiang, China), $75 \mu \mathrm{g} / \mathrm{mL}$ penicillin, $50 \mu \mathrm{g} / \mathrm{mL}$ streptomycin, $0.1 \%(w / v)$ polyvinyl alcohol, and $10 \%(v / v)$ porcine follicular fluid (pFF) [58], covered with $150 \mu \mathrm{L}$ of mineral oil at $38.5^{\circ} \mathrm{C}$ in an atmosphere of $5 \% \mathrm{CO}_{2}$ in humidified air for $44 \mathrm{~h}$.

\subsection{RV Concentration and In Vitro Aging}

RV was dissolved in $10 \mathrm{mmol} / \mathrm{L}$ of Dimethyl Sulfoxide (DMSO) as a stock solution and was stored at $-20{ }^{\circ} \mathrm{C}$ before use. At the start of each culture, the stock solution was diluted with TCM-199 in vitro maturation medium to adjust a final concentration of $2 \mu \mathrm{mol} / \mathrm{L}$ for the RV treatments. For in vitro aging analysis, oocytes were cultured in IVM medium supplemented with or without $2 \mu \mathrm{mol} / \mathrm{L} \mathrm{RV}$ (Control, Aged $24 \mathrm{~h}$, Aged $24 \mathrm{~h}+\mathrm{RV}$, Aged $48 \mathrm{~h}$, and Aged $48 \mathrm{~h}+\mathrm{RV}$ groups, respectively) for an additional $24 \mathrm{~h}$ and $48 \mathrm{~h}$ prolonged aging period at $38.5^{\circ} \mathrm{C}$ supplemented with $5 \% \mathrm{CO}_{2}$ in the humidified air for $44 \mathrm{~h}$. The fresh oocytes without any prolonged culture were used as control group.

\subsection{RNA Isolation and Quantitative Real-Time Polymerase Chain Reaction ( $q R T-P C R$ )}

According to the time-based group differentiation and after maturation $(44 \mathrm{~h})$ of oocytes, the denuded oocytes were collected and washed thrice in DPBS solution and stored at $-80^{\circ} \mathrm{C}$ until the RNA was extracted. A total of 100 oocytes were used for total RNA extraction (in three replicates) from each group using the Trizol ${ }^{\mathrm{TM}}$ Reagent (Thermo Fisher scientific, Waltham, MA, USA). The extracted RNA was quantified using Nano-Drop and stored at $-80{ }^{\circ} \mathrm{C}$ until further use. The first strand of cDNA was synthesized from 2 ug of total RNA with Primer Script ${ }^{\mathrm{TM}}$ RT Master Mix (Takara, Dalian, China) following the manufacturer's described reaction protocol: $37^{\circ} \mathrm{C}$ for $15 \mathrm{~min}, 85^{\circ} \mathrm{C}$ for $5 \mathrm{~s}$, and hold at $4^{\circ} \mathrm{C}$. The synthesized cDNA was subjected to real-time PCR using TB Green ${ }^{\circledR}$ Premix Ex 
$\operatorname{Taq}^{\mathrm{TM}}$ (TaKaRa, Dalian, China). The forward and reverse primer sequences for real-time PCR are listed in Table 1 . The reaction conditions were $30 \mathrm{~s}$ at $95^{\circ} \mathrm{C}$, followed by 40 cycles of $95^{\circ} \mathrm{C}$ for $5 \mathrm{~s}$ and $60^{\circ} \mathrm{C}$ for $30 \mathrm{~s}$. Ultimately, they were quantified at $95^{\circ} \mathrm{C}$ for $15 \mathrm{~s}, 60^{\circ} \mathrm{C}$ for $1 \mathrm{~min}$, and $95^{\circ} \mathrm{C}$ for $15 \mathrm{~s}$. At least three replications were performed for each reaction and data were analyzed using the $2^{-\triangle \triangle \mathrm{CT}}$ method [58].

Table 1. Primer sequences of the target genes used for RT-qPCR.

\begin{tabular}{|c|c|c|c|}
\hline Target Gene & Forward and Reverse Sequence & Product Size (bp) & Accession Number \\
\hline GAPDH & $\begin{array}{l}\text { F: 5'-GTCGGTTGTGGATCTGACCT-3' } \\
\text { R: 5'-TTGACGAAGTGGTCGTTGAG-3' }\end{array}$ & 207 & NM_001206359 \\
\hline Caspase-3 & $\begin{array}{l}\text { F: 5'-CGTGCTTCTAAGCCATGGTG-3' } \\
\text { R: 5'-GTCCCACTGTCCGTCTCAAT-3' }\end{array}$ & 186 & NM_214131 \\
\hline Bcl-2 & $\begin{array}{l}\text { F:5'-AGGGCATTCAGTGACCTGAC-3' } \\
\text { R: } 5^{\prime} \text {-CGATCCGACTCACCAATACC-3' }\end{array}$ & 193 & NM_214285 \\
\hline Bax & $\begin{array}{l}\text { F:5'-TGCCTCAGGATGCATCTACC-3' } \\
\text { R: } 5^{\prime} \text {-AAGTAGAAAAGCGCGACCAC-3' }\end{array}$ & 199 & XM_003127290 \\
\hline CAT & $\begin{array}{l}\text { F-5'-AACTGTCCCTTCCGTGCTA-3' } \\
\text { R-5'-CCTGGGTGACATTATCTTCG-3' }\end{array}$ & 195 & XM_021081498 \\
\hline GPX & $\begin{array}{l}\text { F:GAGCCCTTCAACCTGTCCTC } \\
\text { R:GTCGGACGTACTTCAGGCAA }\end{array}$ & 210 & NC_010455.5 \\
\hline SOD1 & $\begin{array}{l}\text { F-5'-ACCTGGGCAATGTGACTG-3' } \\
\text { R-5'-TCCAGCATTTCCCGTCT-3 }\end{array}$ & 131 & NM_001190422 \\
\hline
\end{tabular}

\subsection{Measurement of Reactive Oxygen Species (ROS) Intensity}

To measure the level of intracellular ROS, DCFH-DA (2, 7-Dichlorodi-hydrofluorescein diacetate) and $10 \mu \mathrm{M}$ working solution (with TCM199 medium), after diluting together, were equilibrated in the incubator at $37^{\circ} \mathrm{C}$ for $30 \mathrm{~min}$ subsequently, and the oocytes were incubated in the DCFH-DA working solution at $37^{\circ} \mathrm{C}$ for $1 \mathrm{~h}$ under total darkness. After incubation, oocytes were washed three times in PBS, and the fluorescence signals were detected and imaged using confocal microscope (Zeiss LSM 700META, Oberkochen, Germany) that was fluorescence intensity of ROS (Excitation wavelength: 450-490 nm and Emission wavelength: $515-565 \mathrm{~nm}$ ). The relative fluorescence intensity was measured with Image 1.5 software (Bethesda, Maryland, USA). Total numbers of 25-30 oocytes (in three replicates) were used for ROS measurement, respectively.

\subsection{Determination of Intracellular GSH Contents}

The contents of total glutathione (T-GSH) were examined through an enzymatic method by using a GSH/GSSG assay kit (Beyotime, Shanghai, China) according to the manufacturer's instructions. A total of 50 oocytes from each group were placed into a small conical tube containing $30 \mu \mathrm{L}$ of protein scavenger M solution supplied with the kit. Afterward, tube contents were vortexed thoroughly for $5 \mathrm{~min}$, then the mixture was frozen at liquid nitrogen for $2 \mathrm{~min}$ and thawed in a water bath at $37^{\circ} \mathrm{C}$ repeatedly for 3 times. Subsequently, mixture was centrifuged at $10,000 \mathrm{rpm}$ for $10 \mathrm{~min}$ at $4^{\circ} \mathrm{C}$ and placed on ice for $5 \mathrm{~min}$ using a 96-well plate. The samples or standard in the sequence were added and mixed accordingly. Immediately, absorbance was observed at $405 \mathrm{~nm}$ with a microplate reader, for $25 \mathrm{~min}$, with a reading recorded for every $5 \mathrm{~min}$. A standard curve was developed for the determination of the GSH content of each sample. The GSH concentration was calculated by dividing the total concentration of each sample by the total number of oocytes present in the sample (pmol/oocyte).

\subsection{Mitochondrial Membrane Potential Assay}

The mitochondrial membrane potential (MMP, $\Delta \varphi m$ ) of the aged and fresh oocytes was evaluated using mitochondrial membrane potential assay kit JC-1 (Beyotime, Shanghai, China). The oocytes were exposed to $10 \mu \mathrm{L} \mathrm{JC}-1$ in $100 \mu \mathrm{L}$ working solution at $38.5^{\circ} \mathrm{C}$ in $5 \% \mathrm{CO}_{2}$ for $20 \mathrm{~min}$ under total darkness. To remove surface fluorescence, oocytes were 
washed three times in PBS and then mounted on glass slides using D-PBS for microscopy. Laser excitation was set at $488 \mathrm{~nm}$ for green and $525 \mathrm{~nm}$ for red fluorescence, respectively. The fluorescence microscope (Zeiss LSM 700 META, Oberkochen, Germany) with the same scan settings for each sample was used to measure the fluorescence intensity of each oocyte. ImageJ 1.5 software (Bethesda, Maryland, USA) was used to analyze the normal fluorescence pixel intensities of each oocyte. The ratio of green to red fluorescence pixels was used to analyze mitochondrial membrane potential.

\subsection{Statistical Analysis}

Each treatment group had a minimum of 3 replicates, and the images of oocytes stained in the same dye were captured with the same scan settings. The average value of fluorescence intensity in each group of oocytes was analyzed after deduction of the background fluorescence through ImageJ software (National Institutes of Health, Bethesda, MD, USA). The obtained data were analyzed by the Statistical Package for Social Sciences (SPSS) software (version18.0) by using one-way analysis of variance (ANOVA). The treatment means were compared by the least significant difference (LSD) test at $1 \%$ and $5 \%$ probability levels. The $p$-value of $<0.05$ was considered a significant difference, while $p<0.01$ was considered as highly significant, and $p<0.001$ was considered as extremely significant.

\section{Conclusions}

Findings of the present study revealed that RV can effectively alleviate the adverse effects of oocyte aging by increasing the expression of antioxidant enzymes while decreasing the ROS level. Additionally, the RV treatment resisted against the decline in mitochondrial membrane potential in aged oocytes. Moreover, RV showed potent antiapoptotic effects by potentially upregulating the expression of Bcl-2 while downregulating the Bax and Caspase 3 transcript levels. Collectively, our findings lead to the evidence that RV may be one of the important constituents in improving the oocyte quality by delaying the antiaging effects through its antioxidant properties on porcine oocytes.

Author Contributions: Conceptualization, B.A. and Y.D.; Methodology, B.A.; Software, B.A.; Validation, B.A., Y.D. and R.R.; Formal analysis, B.A.; Investigation, B.A.; Resources, Y.D.; Data curation, B.A.; Writing —original draft preparation, B.A.; Writing—review and editing, Y.D. and R.R.; Visualization, Y.D.; Supervision, R.R.; Project administration, R.R.; Funding acquisition, R.R. All authors have read and agreed to the published version of the manuscript.

Funding: This study was supported by the Doctoral Program of the Ministry of Education of China (20130097110020) and the Priority Academic Program Development of Jiangsu higher education institutions (PAPD).

Institutional Review Board Statement: All the experiments and procedures compiled with the guideline and were approved by the local ethical committee of the Nanjing Agricultural University (Jiangsu Province, China) with respect to animal experimentation and care of animal under study.

Informed Consent Statement: Informed consent was not required for this experiment.

Data Availability Statement: The data that support the findings of this study are available on a reasonable request from the corresponding author.

Conflicts of Interest: The authors declare no conflict of interest.

Sample Availability: Samples of the compounds are not available from the authors.

\section{References}

1. Ma, W.; Zhang, D.; Hou, Y.; Li, Y.-H.; Sun, Q.-Y.; Sun, X.-F.; Wang, W.-H. Reduced Expression of MAD2, BCL2, and MAP Kinase Activity in Pig Oocytes after In Vitro Aging Are Associated with Defects in Sister Chromatid Segregation During Meiosis II and Embryo Fragmentation After Activation. Biol. Reprod. 2005, 72, 373-383. [CrossRef]

2. Mukherjee, A.; Malik, H.; Saha, A.P.; Dubey, A.; Singhal, D.K.; Boateng, S.; Saugandhika, S.; Kumar, S.; De, S.; Guha, S.K.; et al. Resveratrol treatment during goat oocytes maturation enhances developmental competence of parthenogenetic and hand-made 
cloned blastocysts by modulating intracellular glutathione level and embryonic gene expression. J. Assist. Reprod. Genet. 2014, 31, 229-239. [CrossRef] [PubMed]

3. Saito, H.; Koike, K.; Saito, T.; Nohara, M.; Kawagoe, S.; Hiroi, M. Aging Changes in the Alignment of Chromosomes after Human Chorionic Gonadotropin Stimulation May Be a Possible Cause of Decreased Fertility in Mice. Horm. Res. 1993, 39, $28-31$. [CrossRef] [PubMed]

4. Díaz, H.; Esponda, P. Ageing-induced changes in the cortical granules of mouse eggs. Zygote 2004, 12, 95-103. [CrossRef]

5. Goud, P.; Goud, A.; Laverge, H.; De Sutter, P.; Dhont, M. Effect of post-ovulatory age and calcium in the injection medium on the male pronucleus formation and metaphase entry following injection of human spermatozoa into golden hamster oocytes. Mol. Hum. Reprod. 1999, 5, 227-233. [CrossRef]

6. Díaz, H.; Esponda, P. Postovulatory ageing induces structural changes in the mouse zona pellucida. J. Submicrosc. Cytol. Pathol. 2004, 36, 211.

7. Kovacic, P.; Somanathan, R. Multifaceted Approach to Resveratrol Bioactivity: Focus on Antioxidant Action, Cell Signaling and Safety. Oxid. Med. Cell. Longev. 2010, 3, 86-100. [CrossRef] [PubMed]

8. Tarín, J.J.; Pérez-Albalá, S.; Aguilar, A.; Miñarro, J.; Hermenegildo, C.; Cano, A. Long-term effects of postovulatory aging of mouse oocytes on offspring: A two-generational study. Biol. Reprod. 1999, 61, 1347-1355. [CrossRef]

9. Lord, T.; Aitken, R.J. Oxidative stress and ageing of the post-ovulatory oocyte. Reproduction 2013, 146, R217-R227. [CrossRef]

10. Mailhes, J.B.; Young, D.; London, S.N. Postovulatory Ageing of Mouse Oocytes in Vivo and Premature Centromere Separation and Aneuploidy. Biol. Reprod. 1998, 58, 1206-1210. [CrossRef]

11. Dankert, D.; Demond, H.; Trapphoff, T.; Heiligentag, M.; Rademacher, K.; Eichenlaub-Ritter, U.; Horsthemke, B.; Grümmer, R. Pre- and Postovulatory Aging of Murine Oocytes Affect the Transcript Level and Poly(A) Tail Length of Maternal Effect Genes. PLoS ONE 2014, 9, e108907. [CrossRef]

12. Huang, J.-C.; Yan, L.-Y.; Lei, Z.-L.; Miao, Y.-L.; Shi, L.-H.; Yang, J.-W.; Wang, Q.; Ouyang, Y.-C.; Sun, Q.-Y.; Chen, D.-Y. Changes in Histone Acetylation During Postovulatory Aging of Mouse Oocyte. Biol. Reprod. 2007, 77, 666-670. [CrossRef]

13. Trapphoff, T.; Heiligentag, M.; Dankert, D.; Demond, H.; Deutsch, D.; Fröhlich, T.; Arnold, G.; Grümmer, R.; Horsthemke, B.; Eichenlaub-Ritter, U. Postovulatory aging affects dynamics of mRNA, expression and localization of maternal effect proteins, spindle integrity and pericentromeric proteins in mouse oocytes. Hum. Reprod. 2016, 31, 133-149. [CrossRef]

14. Wang, T.; Gao, Y.-Y.; Chen, L.; Nie, Z.-W.; Cheng, W.; Liu, X.; Schatten, H.; Zhang, X.; Miao, Y.-L. Melatonin prevents postovulatory oocyte aging and promotes subsequent embryonic development in the pig. Aging 2017, 9, 1552-1564. [CrossRef] [PubMed]

15. Arain, M.; Mei, Z.; Hassan, F.; Saeed, M.; Alagawany, M.; Shar, A.; Rajput, I. Lycopene: A natural antioxidant for prevention of heat-induced oxidative stress in poultry. World's Poult. Sci. J. 2018, 74, 89-100. [CrossRef]

16. Kim, W.-J.; Lee, S.-E.; Park, Y.-G.; Jeong, S.-G.; Kim, E.-Y.; Park, S.-P. Antioxidant hesperetin improves the quality of porcine oocytes during aging in vitro. Mol. Reprod. Dev. 2019, 86, 32-41. [CrossRef] [PubMed]

17. Inoue, M.; Sato, E.F.; Nishikawa, M.; Park, A.-M.; Kira, Y.; Imada, I.; Utsumi, K. Mitochondrial Generation of Reactive Oxygen Species and its Role in Aerobic Life. Curr. Med. Chem. 2003, 10, 2495-2505. [CrossRef] [PubMed]

18. Liu, Y.; Fiskum, G.; Schubert, D. Generation of reactive oxygen species by the mitochondrial electron transport chain. J. Neurochem. 2002, 80, 780-787. [CrossRef]

19. Dröge, W. Free Radicals in the Physiological Control of Cell Function. Physiol. Rev. 2002, 82, 47-95. [CrossRef]

20. Redza-Dutordoir, M.; Averill-Bates, D.A. Activation of apoptosis signalling pathways by reactive oxygen species. Biochim. Biophys. Acta BBA Bioenerg. 2016, 1863, 2977-2992. [CrossRef]

21. Liang, S.; Guo, J.; Choi, J.-W.; Shin, K.-T.; Wang, H.-Y.; Jo, Y.-J.; Kim, N.-H.; Cui, X.-S. Protein phosphatase 2A regulatory subunit B55 $\alpha$ functions in mouse oocyte maturation and early embryonic development. Oncotarget 2017, 8, 26979-26991. [CrossRef] [PubMed]

22. Ramalho-Santos, J.; Varum, S.; Amaral, S.; Mota, P.C.; Sousa, A.P.; Amaral, A. Mitochondrial functionality in reproduction: From gonads and gametes to embryos and embryonic stem cells. Hum. Reprod. Updat. 2009, 15, 553-572. [CrossRef] [PubMed]

23. Babayev, E.; Wang, T.; Szigeti-Buck, K.; Lowther, K.; Taylor, H.S.; Horvath, T.; Seli, E. Reproductive aging is associated with changes in oocyte mitochondrial dynamics, function, and mtDNA quantity. Maturitas 2016, 93, 121-130. [CrossRef] [PubMed]

24. Wang, T.; Han, J.; Duan, X.; Xiong, B.; Cui, X.-S.; Kim, N.-H.; Liu, H.-L.; Sun, S.-C. The toxic effects and possible mechanisms of Bisphenol A on oocyte maturation of porcine in vitro. Oncotarget 2016, 7, 32554-32565. [CrossRef]

25. Zhang, D.; Ma, W.; Li, Y.-H.; Hou, Y.; Li, S.-W.; Meng, X.-Q.; Sun, X.-F.; Sun, Q.-Y.; Wang, W.-H. Intra-oocyte Localization of MAD2 and Its Relationship with Kinetochores, Microtubules, and Chromosomes in Rat Oocytes During Meiosis. Biol. Reprod. 2004, 71, 740-748. [CrossRef]

26. Suzuki, Y.; Imai, Y.; Nakayama, H.; Takahashi, K.; Takio, K.; Takahashi, R. A Serine Protease, HtrA2, Is Released from the Mitochondria and Interacts with XIAP, Inducing Cell Death. Mol. Cell 2001, 8, 613-621. [CrossRef]

27. Verhagen, A.M.; Ekert, P.; Pakusch, M.; Silke, J.; Connolly, L.M.; Reid, G.; Moritz, R.L.; Simpson, R.; Vaux, D.L. Identification of DIABLO, a Mammalian Protein that Promotes Apoptosis by Binding to and Antagonizing IAP Proteins. Cell 2000, $102,43-53$. [CrossRef] 
28. Fico, A.; Manganelli, G.; Cigliano, L.; Bergamo, P.; Abrescia, P.; Franceschi, C.; Martini, G.; Filosa, S. 2-deoxy-d-ribose induces apoptosis by inhibiting the synthesis and increasing the efflux of glutathione. Free Radic. Biol. Med. 2008, 45, 211-217. [CrossRef]

29. Papaliagkas, V.; Anogianaki, A.; Anogianakis, G.; Ilonidis, G. The proteins and the mechanisms of apoptosis: A mini-review of the fundamentals. Hippokratia 2007, 11, 108-113.

30. Hoffmann, P.R.; Decathelineau, A.M.; Ogden, C.A.; Leverrier, Y.; Bratton, D.L.; Daleke, D.L.; Ridley, A.; Fadok, V.A.; Henson, P.M. Phosphatidylserine (PS) induces PS receptor-mediated macropinocytosis and promotes clearance of apoptotic cells. J. Cell Biol. 2001, 155, 649-660. [CrossRef]

31. Pervaiz, S.; Holme, A.L. Resveratrol: Its Biologic Targets and Functional Activity. Antioxid. Redox Signal. 2009, 11, $2851-2897$. [CrossRef] [PubMed]

32. Jia, B.-Y.; Xiang, D.-C.; Shao, Q.-Y.; Zhang, B.; Liu, S.-N.; Hong, Q.-H.; Quan, G.-B.; Wu, G.-Q. Inhibitory effects of astaxanthin on postovulatory porcine oocyte aging in vitro. Sci. Rep. 2020, 10, 20217. [CrossRef] [PubMed]

33. Nutt, L.K.; Gogvadze, V.; Uthaisang, W.; Mirnikjoo, B.; McConkey, D.J.; Orrenius, S. Research paper indirect effects of Bax and Bak initiate the mitochondrial alterations that lead to cytochrome c release during arsenic trioxide-induced apoptosis. Cancer Biol. Ther. 2005, 4, 459-467. [CrossRef]

34. May-Panloup, P.; Boucret, L.; De La Barca, J.-M.C.; Desquiret-Dumas, V.; Ferré-L'Hotellier, V.; Morinière, C.; Descamps, P.; Procaccio, V.; Reynier, P. Ovarian ageing: The role of mitochondria in oocytes and follicles. Hum. Reprod. Updat. 2016, 22, 725-743. [CrossRef]

35. Kim, E.N.; Lim, J.H.; Kim, M.Y.; Ban, T.H.; Jang, I.-A.; Yoon, H.E.; Park, C.W.; Chang, Y.S.; Choi, B.S. Resveratrol, an Nrf2 activator, ameliorates aging-related progressive renal injury. Aging 2018, 10, 83-99. [CrossRef] [PubMed]

36. Kwak, S.-S.; Cheong, S.-A.; Jeon, Y.; Lee, E.; Choi, K.-C.; Jeung, E.-B.; Hyun, S.-H. The effects of resveratrol on porcine oocyte in vitro maturation and subsequent embryonic development after parthenogenetic activation and in vitro fertilization. Theriogenology 2012, 78, 86-101. [CrossRef] [PubMed]

37. Zuo, L.; Prather, E.R.; Stetskiv, M.; Garrison, D.E.; Meade, J.R.; Peace, T.I.; Zhou, T. Inflammaging and Oxidative Stress in Human Diseases: From Molecular Mechanisms to Novel Treatments. Int. J. Mol. Sci. 2019, 20, 4472. [CrossRef]

38. Yang, L.; Chen, Y.; Liu, Y.; Xing, Y.; Miao, C.; Zhao, Y.; Chang, X.; Zhang, Q. The Role of Oxidative Stress and Natural Antioxidants in Ovarian Aging. Front. Pharmacol. 2021, 11, 617843. [CrossRef]

39. Birben, E.; Sahiner, U.M.; Sackesen, C.; Erzurum, S.; Kalayci, O. Oxidative stress and antioxidant defense. World Allergy Organ. J. 2012, 5, 9-19. [CrossRef]

40. McCord, J.M. The evolution of free radicals and oxidative stress. Am. J. Med. 2000, 108, 652-659. [CrossRef]

41. Therond, P. Oxidative stress and damages to biomolecules (lipids, proteins, DNA). Ann. Pharm. Fr. 2006, 64, 383-389. [CrossRef]

42. Liang, Q.-X.; Lin, Y.-H.; Zhang, C.-H.; Sun, H.-M.; Zhou, L.; Schatten, H.; Sun, Q.-Y.; Qian, W.-P. Resveratrol increases resistance of mouse oocytes to postovulatory aging in vivo. Aging 2018, 10, 1586-1596. [CrossRef]

43. Jia, Z.; Zhu, H.; Misra, B.R.; Mahaney, J.E.; Li, Y.; Misra, H.P. EPR studies on the superoxide-scavenging capacity of the nutraceutical resveratrol. Mol. Cell. Biochem. 2008, 313, 187-194. [CrossRef] [PubMed]

44. De La Lastra, C.A.; Villegas, I. Resveratrol as an antioxidant and pro-oxidant agent: Mechanisms and clinical implications. Biochem. Soc. Trans. 2007, 35, 1156-1160. [CrossRef] [PubMed]

45. Park, J.-W.; Choi, Y.-J.; Suh, S.-I.; Baek, W.-K.; Suh, M.-H.; Jin, I.-N.; Min, D.S.; Woo, J.-H.; Chang, J.-S.; Passaniti, A.; et al. Bcl-2 overexpression attenuates resveratrol-induced apoptosis in U937 cells by inhibition of caspase-3 activity. Carcinogenesis 2001, 22, 1633-1639. [CrossRef]

46. Wenzel, E.; Soldo, T.; Erbersdobler, H.; Somoza, V. Bioactivity and metabolism of trans-resveratrol orally administered to Wistar rats. Mol. Nutr. Food Res. 2005, 49, 482-494. [CrossRef]

47. Wu, J.Q.; Kosten, T.R.; Zhang, X.Y. Free radicals, antioxidant defense systems, and schizophrenia. Prog. Neuro Psychopharmacol. Biol. Psychiatry 2013, 46, 200-206. [CrossRef]

48. Meng, Q.; Guo, T.; Li, G.; Sun, S.; He, S.; Cheng, B.; Shi, B.; Shan, A. Dietary resveratrol improves antioxidant status of sows and piglets and regulates antioxidant gene expression in placenta by Keap1-Nrf2 pathway and Sirt1. J. Anim. Sci. Biotechnol. 2018, 9, 34. [CrossRef]

49. Wu, C.-C.; Huang, Y.-S.; Chen, J.-S.; Huang, C.-F.; Su, S.-L.; Lu, K.-C.; Lin, Y.-F.; Chu, P.; Lin, S.-H.; Sytwu, H.-K. Resveratrol Ameliorates Renal Damage, Increases Expression of Heme Oxygenase-1, and Has Anti-Complement, Anti-Oxidative, and Anti-Apoptotic Effects in a Murine Model of Membranous Nephropathy. PLoS ONE 2015, 10, e0125726. [CrossRef]

50. Movahed, A.; Yu, L.; Thandapilly, S.J.; Louis, X.; Netticadan, T. Resveratrol protects adult cardiomyocytes against oxidative stress mediated cell injury. Arch. Biochem. Biophys. 2012, 527, 74-80. [CrossRef] [PubMed]

51. Soeur, J.; Eilstein, J.; Léreaux, G.; Jones, C.; Marrot, L. Skin resistance to oxidative stress induced by resveratrol: From Nrf2 activation to GSH biosynthesis. Free Radic. Biol. Med. 2015, 78, 213-223. [CrossRef] [PubMed]

52. Lodovici, M.; Bigagli, E.; Luceri, C.; Manni, E.M.; Zaid, M. Protective Effect of Resveratrol against Oxidation Stress Induced by 2-Nitropropane in Rat Liver. Pharmacol. Pharm. 2011, 2, 127-135. [CrossRef]

53. Gebauer, F.; Xu, W.; Cooper, G.; Richter, J. Translational control by cytoplasmic polyadenylation of c-mos mRNA is necessary for oocyte maturation in the mouse. EMBO J. 1994, 13, 5712-5720. [CrossRef] [PubMed] 
54. Yew, N.; Mellini, M.L.; Martinez, C.K.; Woude, G.F.V. Meiotic initiation by the mos protein in Xenopus. Nature 1992, 355, 649-652. [CrossRef]

55. Pascuali, N.; Scotti, L.; Abramovich, D.; Irusta, G.; Di Pietro, M.; Bas, D.; Tesone, M.; Parborell, F. Inhibition of platelet-derived growth factor (PDGF) receptor affects follicular development and ovarian proliferation, apoptosis and angiogenesis in prepubertal eCG-treated rats. Mol. Cell. Endocrinol. 2015, 412, 148-158. [CrossRef]

56. Tong, Z.; Xie, Y.; He, M.; Ma, W.; Zhou, Y.; Lai, S.; Meng, Y.; Liao, Z. VDAC1 deacetylation is involved in the protective effects of resveratrol against mitochondria-mediated apoptosis in cardiomyocytes subjected to anoxia/reoxygenation injury. Biomed. Pharmacother. 2017, 95, 77-83. [CrossRef] [PubMed]

57. Brunelle, J.K.; Letai, A. Control of mitochondrial apoptosis by the Bcl-2 family. J. Cell Sci. 2009, 122, 437-441. [CrossRef]

58. Shi, F.; Li, W.; Zhao, H.; He, Y.; Jiang, Y.; Ni, J.; Abbasi, B.; Rui, R.; Ju, S. Microcystin-LR exposure results in aberrant spindles and induces apoptosis in porcine oocytes. Theriogenology 2020, 158, 358-367. [CrossRef] 